\title{
Investigation of Cracking in Additively Manufactured IN718 by Correlative Tomography
}

\author{
B. Winiarski ${ }^{1,2}$, G. Pyka ${ }^{1}$, C.A. Wade ${ }^{4}$, A. Chirazi ${ }^{3}$, D. Lichau ${ }^{3}$, G.M. Burke ${ }^{4}$, and P.J. Withers ${ }^{2}$ \\ 1. Thermo Fisher Scientific, Vlastimila Pecha 12, Brno, Czech Republic \\ 2. Henry Moseley X-ray Imaging Facility, School of Materials, The University of Manchester, U.K. \\ 3. Thermo Fisher Scientific, Impasse Rudolf Diesel, Bât A, Mérignac, Bordeaux, France. \\ 4. Materials Performance Centre, School of Materials, University of Manchester, U.K.
}

Three-dimensional (3D) correlative multimodal tomography (CMT) is a powerful and versatile materials and life sciences research workflow [1, 2, 3]. For the same region of interest and at different lengthscales it allows spatial registration in two and three dimensions of many imaging modalities - light, electron/ion microscopy, X-Ray tomography, EBSD, EDS, Raman, Cathodoluminescence, etc.

The advent of Additive Manufacturing (AM) methods [4], e.g. Selective Laser Melting (SLM) of powder bed, Blown Powder Laser Deposition (BPLD), etc. promises overcoming the limitations of the conventional metallurgical routes particularly for small production volumes, parts with complex configurations, near net-shape dimensions, high performance requirements and parts repair/cladding, e.g. of Inconel alloys. Inconel 718 (IN718) belongs to a family of nickel-based superalloys widely used in aircraft turbines, jet engines and steam turbine power plants, etc., due to their high temperature corrosion, fatigue and creep resistance [5]. The desirable microstructure of IN718 components should consists $\gamma$ solid supersaturated solution matrix (rich in $\mathrm{Ni}, \mathrm{Cr}$ and $\mathrm{Fe}$ ) primarily strengthened by $\gamma^{\prime \prime}-\mathrm{Ni}_{3} \mathrm{Nb}$ and $\gamma^{\prime}-\mathrm{Ni}_{3}(\mathrm{Al}, \mathrm{Ti})$ precipitates $[5,6]$. However, $\mathrm{Nb}$ is highly susceptible to segregations and tend to form undesirable brittle phases, e.g. $\mathrm{NbC}, \delta-\mathrm{Ni}_{3} \mathrm{Nb}$ and Laves phases $(\mathrm{Ni}, \mathrm{Cr}, \mathrm{Fe})(\mathrm{Nb}$, $\mathrm{Mo}, \mathrm{Ti})$, together with residual stresses impairing tensile ductility, fatigue and creep properties $[5,6]$.

In this contribution we use CMT to investigate cracking in Blown Powder Laser Deposited (BPLD) IN718 coupons produced with $5 \mathrm{~kW}$ laser power, 750 and $1250 \mathrm{~mm} / \mathrm{min}$ feed. CMT is supported with latest HeliScan ${ }^{\mathrm{TM}}$ micro X-Ray CT system and Helios ${ }^{\mathrm{TM}}$ Plasma FIB - SEM DualBeam ${ }^{\mathrm{TM}}$ and Talos ${ }^{\mathrm{TM}}$ STEM microscopes and unique, software integrated instrumental environment using inter-linked software: Auto Slice\&View $4^{\mathrm{TM}}$, Avizo $^{\mathrm{TM}}, \mathrm{iFAST}^{\mathrm{TM}}$, Maps $^{\mathrm{TM}}$ and AutoScript ${ }^{\mathrm{TM}}$.

At the macroscale we observed large mm-long open cracks developed near the base of coupon and on the interface (Fig. 1a). These cracks form along grain boundaries of large columnar/dendritic grains (see EBSD map). The typical weld-like microstructure related to deposition passes is not observed. Visualization of micro CT data shows network of cracks across the thickness of component (Fig. 1b). Micron scale results indicate that cracks develop in the $\mathrm{Nb}$ enriched regions (zones with elements segregation and network of Laves phases - Fig. 1c). Porosity and large $30 \mu \mathrm{m}$ diameter pore is observed inside a grain. At the nanoscale (Fig. 1d) we observed $\gamma^{\prime \prime}$, Aluminum Oxide, Titanium Nitride, Niobium Carbide precipitates. The combined capabilities of hardware and software allowed obtaining a new 3D insight into manufacturing defects developed during Blown Powder Laser Deposition.

References:

[1] Winiarski, B. et al, S. of Microscopy and Microanalysis, 152 (2017), p. S4.

[2] Winiarski, B. et al, Microscopy and Microanalysis 23(S1) (2017), p. 342.

[3] Burnett, T.L. et al, Scientific Reports 4 (2014), p. 4711.

[4] Bi, G. et al, Surface \& Coatings Technology 201 (2006), p. 2676.

[5] Reed, R. The Superalloys-Fundamentals and Applications. Cambridge Uni. Press, 2008

[6] Parimi, L.L. et al, Proc. of $12^{\text {th }}$ International Symposium on Superalloys (2012), p. 511. 

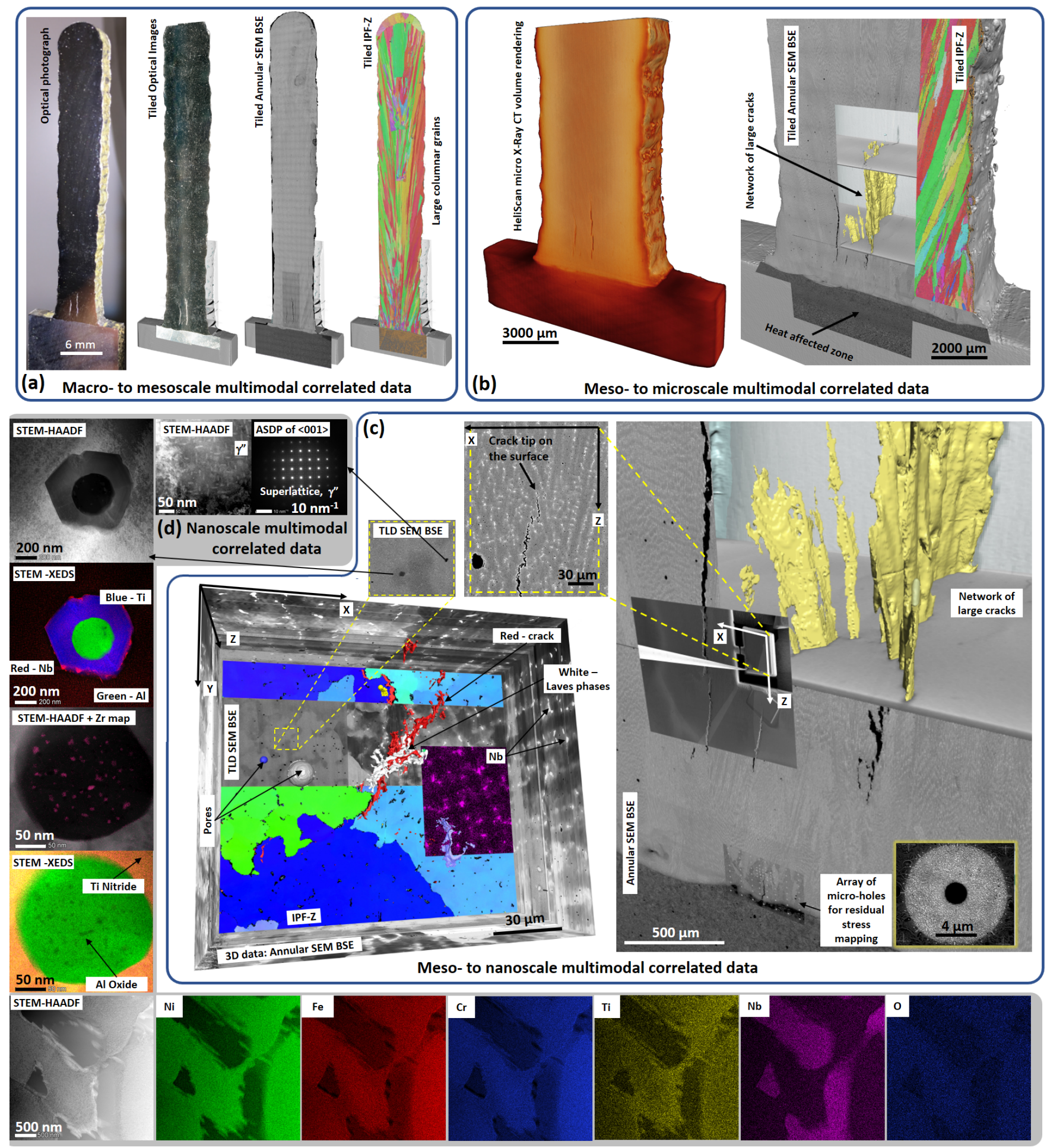

Figure 1. 3D multiscale and multimodal results (laser power $5 \mathrm{~kW}$ with feed $1250 \mathrm{~mm} / \mathrm{min}$, powder feed rate $40 \mathrm{~g} / \mathrm{min}, 84$ layers with area $115 \times 7 \mathrm{~mm}^{2}, 0.5 \mathrm{~mm}$ layer height offset). a) Investigation using tiling and stitching; OM $4.5 \mu \mathrm{m} / \mathrm{pix}$, SEM $0.65 \mu \mathrm{m} /$ pix, EBSD $10 \mu \mathrm{m} /$ pix. b) micro CT volume with coregistrated SEM and raw EBSD maps. c) on the right zoomed in region with cracks and location from where a large chunk (with a crack tip) was resected for further 3D PFIB serial sectioning study (100 $\mathrm{nm}^{3}$ voxel); on the left visualization of the crack tip region with coregistrated raw EBSD and EDX information. Note: SEM TLD BSE and Annular BSE (CBS) signals were collected simultaneously. d) STEM study revealed $\gamma$ ", Aluminum Oxide, Titanium Nitride, Niobium Carbide precipitates, $\mathrm{Nb}$ rich Laves phases and elements segregation. 